\title{
GENETIC VARIABILITY IN MORPHOLOGICAL AND PHYSIOLOGICAL TRAITS WITHIN AND AMONG RICE SPECIES AND THEIR INTERSPECIFIC PROGENIES
}

\author{
R. G. GUEI ${ }^{1 *}$, F. J. ABAMU1, T. KARIM ${ }^{1}$, and S. NAMAN ${ }^{2}$ \\ ${ }^{1}$ West Africa Rice Development Association, 01 B.P. 2551 Bouaké 01, Côte d'Ivoire \\ *Email : r.guei@cgiar.org \\ ${ }^{2}$ Ecole d'agriculture d'Adzopé, Côte d'Ivoire
}

\begin{abstract}
This study compares genetic variation in morpho-physiological traits within and among five groups of Oryza species. Several morphological and phenological characters were measured in field trials. Results showed that genetic variation exits among and within these groups for the characters measured. More $O$. glaberrima and traditional $O$. sativa possess attributes which indicate they are better adapted to suboptimal growing conditions that characterize rice cultivation in West Africa, but are poor yielding. The interspecific progenies possess characters that cover the range of both their parents. Cluster analysis amalgamated some as possessing the adaptive morphological traits of their O.glaberrima parents, and the panicle and yield attributes of improved $O$. sativa parents. O. sativa of temperate origin, but of tropical japonica genetic background did not show characters for adaptability to the West African upland conditions, but was similar to interspecifics and other adapted genotypes groups that possess panicle and spikelet characteristics. Those ones could be exploited for extending present yield levels.
\end{abstract}

Keywords : Germplasm characterization, Oryza glaberrima, Oryza sativa, genetic variation, West Africa.

\section{RESUME}

\section{VARIABILITE GENETIQUE DES TRAITS MORPHOLOGIQUES ET PHYSIOLOGIQUES CHEZ LES ESPECES DE RIZ} ET LEURS DESCENDANCES INTERSPECIFIQUES

Cette étude compare la variation génétique de paramètres morpho-physiologiques au sein et entre cinq groupes d'espèces Oryza. Plusieurs caractères morphologiques et phénologiques ont été mesurés dans des essais conduits au champ. Les résultats ont montré qu'il existe, pour les caractères mesurés, une variation génétique au sein et entre les groupes étudiés. Un nombre important d'espèces 0 . glaberrima et O. sativa traditionnelles ont des attributs qui indiquent qu'elles sont mieux adaptées aux conditions suboptimales de la culture de riz en Afrique occidentale. Elles ont, cependant, un rendement faible. Les descendants interspécifiques possèdent des attributs qui couvrent la gamme des caractères de leurs parents. L'analyse de groupement a identifié certains comme présentant les caractères morphologiques d'adaptation de leurs parents $\mathrm{O}$. glaberrima, et des caractères de panicule et de rendement des parents améliorés $\mathrm{O}$. sativa. Les espèces $\mathrm{O}$. sativa d'origine tempérée, mais de fond génétique japonica tropical n'ont pas démontré une capacité d'adaptation aux conditions de culture de riz pluvial en Afrique de l'Ouest. Par contre, elles étaient semblables aux descendants interspécifiques et autres groupes de génotypes adaptés quant aux caractéristiques des panicules et des grains. Celles-ci pourraient être exploitées pour l'amélioration des niveaux de rendement actuels.

Mots-clés : Caractérisation de germplasm, Oryza glaberrima, Oryza sativa, variation génétique, Afrique de l'Ouest.

\section{INTRODUCTION}

The conservation, management, distribution and utilization of genetic resources necessitate and pre-suppose that the germplasms are fully characterized. The Genetic Resources Unit (GRU) at WARDA holds a wide range of rice accessions varying from wild species to improved varieties. They include Oryza glaberrima Steud, a native rice of African origin, several improved 
varieties and landraces of $O$. sativa introduced from other continents, and the interspecific progenies recently obtained from crosses between 0 . glaberrima $x 0$. sativa (Jones et al., 1997). Studies by Singh et al. (1996), indicated that genetic variability exists for many useful traits like early maturity, grain quality, secondary branches in panicle in O. glaberrima. Jones et al. (1997) also revealed wide variation in important morphological and agronomic traits such as seedling vigor, the number of panicles per square meter and growth duration within $O$. glaberrima and traditional $O$. sativa accessions. In characterizing competitiveness among cultivars, Johnson et al. (1996) found that by the end of season-long competition with weeds, O. glaberrima had less weed than improved $O$. sativa types. The mechanism causing less weeds in glaberrima was attributed to larger number of tillers, more leaves, higher leaf area index and specific leaf area (SLA). More information on specific characters, on fundamental differences and similarities among all categories of germplasm viz. traditional landraces, cultivars of $O$. glaberrima, glaberrima x sativa interspecific progenies and improved $O$. sativa are needed and would contribute in enhancing and accelerating ongoing rice improvement work.

The study reported here was undertaken to characterize upland rice accessions currently available and being distributed through the International Network for Genetic Evaluation of Rice in Africa (INGER-Africa). Because of fast genetic erosion in this region and the request for germplasm restoration to farmers in war affected areas, this comparative study is necessary to better characterize the available land races and introductions in comparison with improved $O$. sativa, O. glaberrima and new $O$. glaberrima $\times 0$. sativa interspecific progenies in order to facilitate a better utilization. It will help understand differences and similarities between germplasm accessions groups, and determine the magnitude of genetic variation in our gene-bank.

\section{MATERIALS AND METHODS}

Trials were conducted in an upland rice field during 1998 growing season at the WARDA main research center, Mbe, Cote d'Ivoire. Mbe is located in the guinea-savanna zone $\left(5^{\circ} 06^{\prime} \mathrm{W}\right.$, $7^{\circ} 52^{\prime} \mathrm{N}$ ), and is characterized by an annual rainfall of $1146 \mathrm{~mm}$ and average daily temperature of $25^{\circ} \mathrm{C}$. The soil in the area is an alfisol, with a loamy sand texture and frequent iron concretions.

\section{TREATMENTS}

Three hundred and ninety three (393) rice genotypes originating from different countries and institutions in Africa, Asia, and The Americas (table 1) were used as treatment entries in the trial. Genotypes were in five treatment groups in which all entries of a species, subspecies are clumped to form a treatment. Number of entries per treatment group and a brief description of group members are in table 1.

Table 1 : Arbitrary classification of 393 rice genotypes characterized for morpho-physiological traits during 1998 at WARDA, Mbe Cote d'Ivoire

Classification arbitraire de 393 génotypes de riz caractérisés pour leurs caractères morphophysiologiques. ADRAO, 1998, Mbé, Côte d'Ivoire

\begin{tabular}{|c|c|c|c|}
\hline Genetic Description & $\begin{array}{l}\text { Group } \\
\text { code }\end{array}$ & $\begin{array}{l}\text { No. of } \\
\text { Entries }\end{array}$ & Remarks \\
\hline O. glaberrima & $\mathbf{G}$ & 11 & $\begin{array}{l}\text { Native O. glaberrima lines collected in West Africa, } \\
\text { including parents of the interspecifics in group- } 2 \text {. }\end{array}$ \\
\hline $\begin{array}{l}\text { O. glaberrima } \times \text { O. sativa } \\
\text { interspecific progenies }\end{array}$ & $\mathbf{P}$ & 20 & $\begin{array}{l}\text { Obtained from the interspecific hybridization project at } \\
\text { WARDA. }\end{array}$ \\
\hline $\begin{array}{l}\text { Temperate Oryza sativa, with } \\
\text { tropical japonica genetic } \\
\text { background }\end{array}$ & $\mathbf{U}$ & 9 & $\begin{array}{l}\text { Introduced in the year } 1998 \text { from the USDA germplasm } \\
\text { enhancement center in Arkansas, USA. }\end{array}$ \\
\hline Improved $O$. sativa lines & $\mathbf{W}$ & $319^{*}$ & $\begin{array}{l}\text { A large number of } O \text {. sativa already released and largely } \\
\text { cultivated by farmers in different West African countries, } \\
\text { and lines developed or selected at WARDA, including } \\
\text { parents of the interspecific progenies in group- } 2 \text {. }\end{array}$ \\
\hline $\begin{array}{l}\text { Traditional O. sativa / } \\
\text { landraces }\end{array}$ & $\mathbf{T}$ & $34^{*}$ & $\begin{array}{l}\text { Received in the year } 1996 \text { from the national research } \\
\text { institute (IDESSA) in Côte d'Ivoire }\end{array}$ \\
\hline
\end{tabular}

${ }^{*} \mathrm{~A}$ subset of 20 genotypes representative of the group was used in cluster analysis.

* un sous-échantillon de 20 génotypes représentatifs du groupe a été utilisé dans l'analyse de groupement. 


\section{TRIAL SET-UP AND EXPERIMENTAL DESIGN}

Experimental area has been disc plowed and harrowed twice. One hundred and fifty (150) kg/ ha of compound fertilizer (NPK 15-15-15) was applied as basal. Top dressing was done with two split applications of $50 \mathrm{~kg} / \mathrm{ha}$ each of urea (46\%) at 35 and 65 days after sowing (DAS). Experiment was conducted on 27 July 1998 on plots $5 \mathrm{~m}$ long $x 1 \mathrm{~m}$ wide. Two-three seeds were dibbled at hill spacing of $0.2 \mathrm{~m}$ on row. A distance of $0.5 \mathrm{~m}$ was maintained between plots. The experiment design was completely randomized, with three replications.

During the dry spell, supplementary irrigation was provided from an overhead sprinkler source to maintain soil moisture at field capacity.

\section{DATA COLLECTION AND ANALYSIS}

Data were collected on the two middle rows, a border row on either side being left. Tillers production (number /plant), specific leaf àrea (SLA, calculated as leaf surface area dry weight of the same leaf $\left[\mathrm{m}^{2} / \mathrm{kg}\right]$ ) and seedling vigor were measured at $30 \mathrm{DAS}$. Occurrence of diseases including leaf blast, neck blast, brown spot, stalk rot and insect pest (stem borers and gall midge) were also noted. The characterization of seedling vigor and reaction to diseases/insect pests were based on a 1-9 scoring scale (1= best ; $9=$ poorest) as described in the Standard Evaluation System (SES) for rice (IRRI, 1998). Date of $50 \%$ of flowering were also recorded when occurred, while at physiological maturity, plant height $(\mathrm{cm})$ was measured. Grain yield and yield components including 1000-grain weight (g), grain-to-shoot dry matter ratio or harvest index (g grain/g shoot weight), panicle length $(\mathrm{cm})$, panicle exertion $(\mathrm{cm})$, primary and secondary branching (number/panicle), and spikelet count (number/panicle) were measured at harvest.
Data collected were subjected to appropriate statistical analysis using SAS to describe means and variability within and between groups. Hierarchical cluster analyses were carried out to measure the extent of the inherent diversity within and across all the rice groups, using the various characteristics measured. The amalga-mation method used was «Complete linkage». In the procedure, the distance between two clusters is computed from the maximum euclidean distance between an observation in one cluster and an observation in the other cluster. This method was used because the genotypes actually belong to five (5) clumps as presented in table 1 . For group $T(n=34)$ and group $W(n=319)$ only a subset of 20 entries, representative of the members of a group was used for the cluster analysis.

$\mathrm{K}$-means clustering, with $\mathrm{K}=5$ was also carried out. The purpose is to crosscheck if the genotypes can be amalgamated as described in table 1. Cluster analysis was performed with STATISTICA(SPSS, 1995).

\section{RESULTS AND DISCUSSION}

Variability in the different morphological and physiological traits is summarized in table 2 . Means and coefficient of variability (CV \%) were calculated with regard to actual sample size $(n)$ in each group.

The CV's of the means are high for the disease/ pest resistance rating (e.g. $\mathrm{CV}$ for neck blast $=$ $375 \%$ ) because data are the scores done on scaling of 1 to 9 , therefore need to be interpreted differently. Otherwise, among the quantitatively measured traits, the variability in grain yield (g/plant) varied most ( $\mathrm{CV}=83 \%$ ), followed by the variability in grain-to-shoot dry matter ratio (cv $\approx 57 \%$ ). Variability in tiller number and SLA was between 23 and $29 \%$. Plant height, days to flower and panicle length were the least diverse traits ( $C V \leq 16 \%)$. 


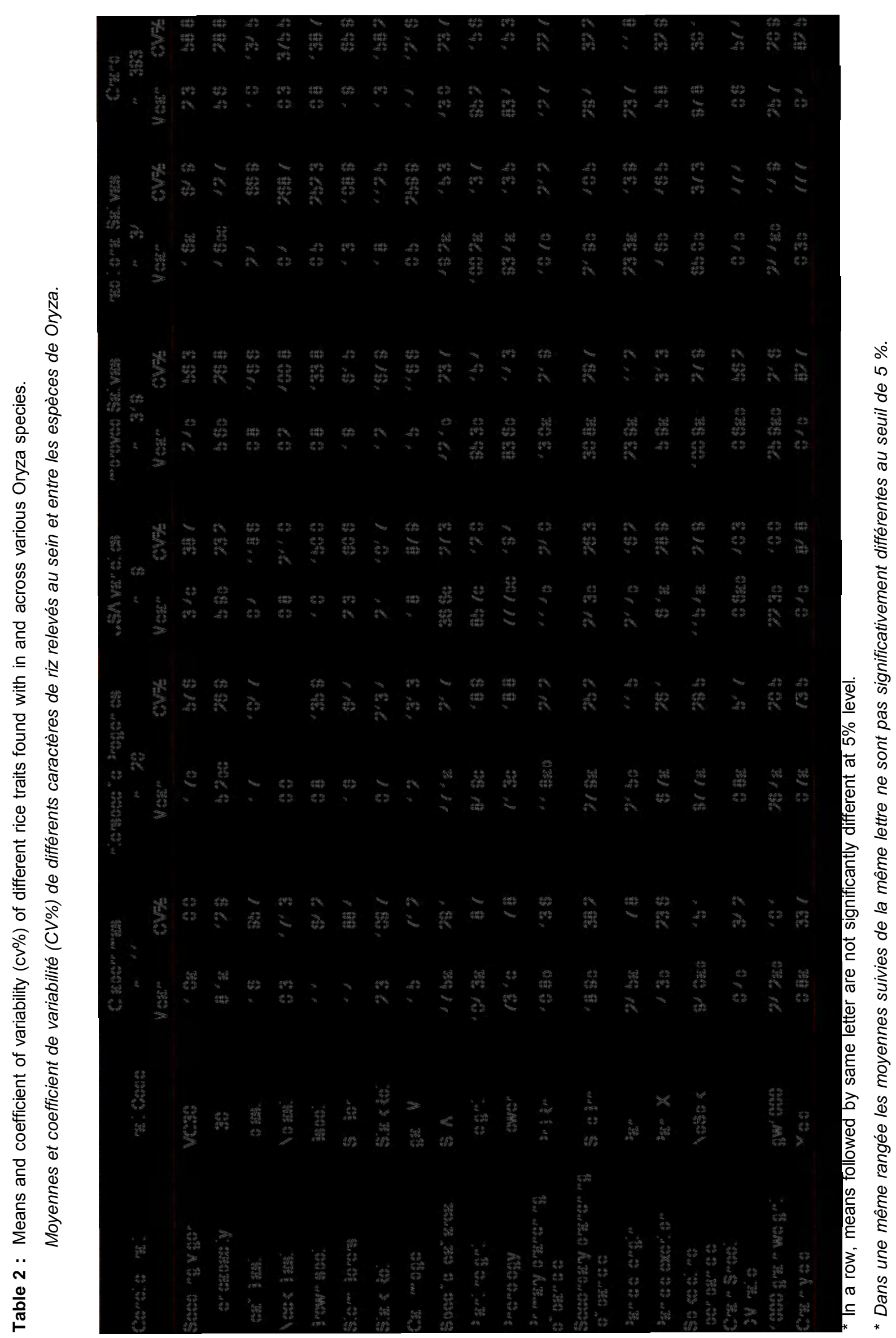




\section{COMPARISON OF VARIABILITY WITH SPECIFIC GENETIC GROUPS}

\section{Morphology and phenological characteristics}

The glaberrimas had the highest mean tiller number and the best seedling vigor, but the CVs associated with these traits were small (12 and $0 \%$ respectively). Genetic variation in plant height and days to flower were also small in the glaberrima group while higher variation in seedling vigor and tillering occurred in the traditional sativas (table 2).

Genetic means for seedling vigor, tillering ability, SLA, primary and secondary branching were low in the USA varieties. This group had shorter straw height and duration to flowering, but is more varied than the glaberrimas in a few properties (table 2). This indicates that the group could be exploited for those traits which CVs are high. Means show that the glaberrimas and the traditional sativas were the tallest among the varietal groups, this can explain the common lodging of these groups (Jones et al., 1997). The lodging of straws in tall varieties, according to Japanese scientists, is due to low tensile strengths of the straw. Shorter straw-height and leaf sheath covering enable rice to tolerate heavier load and avoid lodging (Ookawa and Ishihara, 1993). The US varieties and the Interspecific progenies were similar, and had shorter plant types (table 2). The similarity indicates that interspecific progenies originally developed for low input systems in West Africa (Jones et al., 1997, Dingkuhn et al., 1997) could suit the high-input mechanized harvesting system to which US varieties are adapted.

The variability in SLA of the US varieties was of $27 \%$ and compares to $29 \%$ among the glaberrimas. But the mean of SLA was the lowest among the US varieties and the highest in the glaberrimas, interspecific progenies and traditional sativas, which were statistically at par $(p<0.05)$. Glaberrimas and interspecific progenies have been reported in previous studies to possess high SLA which was linked to superior competitiveness against weeds (Jones et al., 1997; Johnson et al., 1997). Relatively low SLA, seedling vigor and tillering capacity observed among the USA group suggest that, although these germplasm possess tropicaljaponica genetic background, their evolution elsewhere makes them less adapted to West African environments.

\section{Panicle characteristics and grain yield attributes}

Improved sativas were superior or at par with the best in grain yield and panicle characteristics except grain yield $(p<0.05)$. The highest plant yields were obtained with glaberrimas, although this group had the smallest CV in this trait. Variability in yield among the improved sativas and the US varieties were approximately $84 \%$ showing that considerable gains can be obtained by further improvement of these germplasms for yield per se.

The highest variation in the secondary branching was found among the traditional sativas ( $\mathrm{CV}=$ $40.5 \%$ ), although this group did not show the highest means ( $p<0.05$, table 2$)$. The glaberrimas had the lowest number of secondary branches per panicle, with a $38 \%$ of variability in the trait.

Panicle exertion and panicle length, criteria often used by West African rice farmers and women harvesters in adopting a variety, were the best among the improved sativas, and this group also varied the most in panicle exertion. Nearly equal but higher amount of genetic variation in panicle length exists in all non-glaberrima groups.

Differences in spikelet numbers among glaberrimas, interspecific progenies, US varieties, and improved sativas were not statistically significant. However, they had higher mean spikelet number than the traditional sativas. Interestingly, the widest genetic variability of the trait occurred in the traditional sativas indicating opportunities for further exploitation and improvement.

Grain yield, grain-to-shoot index and 1000-grain weight were high in interspecific progenies. The glaberrima and improved sativa were either par or lower than the interspecific progenies (table 2). Genetic variability in grain yield was large in all $(\mathrm{CV}=73-84 \%)$ but glaberrima groups (CV = $33 \%$ ). Jones et al. (1997) have also reported low variability in glaberrima grain yield. Glaberrimas due to its long history of cultivation and mass selection in West Africa became fully adapted to local environments and the genetic base is approaching or are already at their highest level for yield. The lack of genetic variability for yield makes it difficult to obtain further genetic gain through varietal improvement of glaberrimas per se. 


\section{CLUSTER ANALYSIS AND ACROSS SPECIES GENOTYPIC GROUPING}

Figures 1, 2 and 3 present three diagrams of hierarchical clustering of 80 genotypes (cases) across the five groups, based on complete linkage euclidean distances of mean data obtained from 3 replications. The basis of clustering in Figure 1 is the reaction of individual entry to specific diseases / pests - leaf blast, neck blast, brown spot, stem borer and gall midge. Results indicate that at $20 \%$ relative euclidean linkage distance level (Dlink/Dmax ${ }^{*} 100$ ), 80 genotypes can be amalgamated to 31 clusters.

The number of clusters can be synthesized to only 7 at $60 \%$ level, and three at $80 \%$ level. Of these, genotype T25 is obviously an out-lier with respect to overall reaction to stresses. T25 amalgamated only at $100 \%$ level. Table 3 shows that genotype T25 (IR644-1-63-1-1) is a lowland variety developed with Asian parents (IR8 and TN1) and introduced from the USA. This variety was seriously affected by stalk rot (score $=9$ ), brown spot (score $=5$ ), and stem borers $($ score $=3$ ). Its panicle exertion and plant yield were also very poor.

Clustering based on morphological and physiological traits: plant height, days to flower, seedling vigor and SLA (figure 2) revealed that the 80 entries can be amalgamated to 21 clusters assuming that a relative euclidean linkage distance level is of $20 \%$. At the $80 \%$ linkage level, the 80 entries are amalgamated into three groups of which groups the first and the third are more or less of the same size.

Figures 2 and 3 clearly show that diversity in morphological traits are larger than those observed in yield and panicle characteristics. This means that faster genetic gains in rice improvement could be achieved by exploiting the wide diversity that exists in morphophysiological characteristics of breeding materials, rather than in focus directly on their yield. In a breeding program, chances of producing individuals with similar attributes are higher when yield and panicle attributes are considered as priority than in the one where morpho-physiological attributes and disease reaction are considered.

The first group contains mainly glaberrima entries (G8, G7, G3, G2, G1, G5), T26 and W82. All glaberrimas are TOG from Nigeria. T26 (ALAKO), (table 3) is an introduction from Gambia, where O. glaberrima is believed to have originated from Casamance area in Sene-gambia river valley. T26 (ALAKO) is likely to be genetically linked to glaberrima. The variety W82 (IR47686-09-2-4) on the other hand, was developed in Asia by using as parent IRAT104, an improved sativajaponica adapted to West African upland rice conditions (Abamu et al., 1992) and Palawan a traditional upland rice in the Philippines. Therefore, the presence of W82 (IR47686-09-24 ) in this group may be due to IRAT104.

The second group contains progenies $\mathrm{P} 14, \mathrm{P} 10$, P9, P12, P11, P2, P13, P4, P3, W1, and U7 (figure 2). W1 (AMISTAD) originates from Cuba, whereas U7 is NORIN20 from Japan. These two plants are similar but different from interspecific progenies (amalgamated point $=38 \%$ ). W1 185 (UPR103-80-1-2) though statistically linked to interspecific progenies by its morphology, is a lowland variety developed in India. The third and largest group at $80 \%$ level contains most traditional and improved sativas, two interspecific progenies, three glaberrimas, and eight American varieties.

The classification based on yield and panicle parameters (figure 3) gave more agglomeration and fewer clusters. At $20 \%$ relative linkage level for example, the 80 genotypes can be amalgamated into 10 groups, whereas at $40 \%$ and $80 \%$ the data are respectively synthesized to 4 and 2 groups.

The figure 2 also shows that 11 traditional sativas (including T25, T15, T3 ... T5) and W124 are grouped together. This group consists of all varieties but two introduced from national program in Côte d'Ivoire. T25 is a lowland variety developed in Asia and introduced from the USA. Varieties from Côte d'Ivoire not clustered with this group are T2 (IS766) and T11 (IS914). Yield and panicle characteristics of T11 are similar at $5 \%$ linkage level to those of progenies P10 (WAB450-B-16A1-7) and P6 (WAB450-4-1A20), whereas $T 2$ is similar to glaberrima $\mathrm{G} 11$ (CG20), traditional sativa T32 (TAMBA YEGUETI) and W27 (CT6946-9-1-2-M-1P) at $10 \%$ linkage level (Figure 3 ).

To provide insight into the arbitrary groupings shown in table 2, the K-means clustering was performed if the genotypes can be amalgamated in keeping with the table. This information has relevance to programs such as INGER, which has responsibility for germplasm support to a wide range of NARS. Due to their resource constraints, NARS often request for fewer sets 


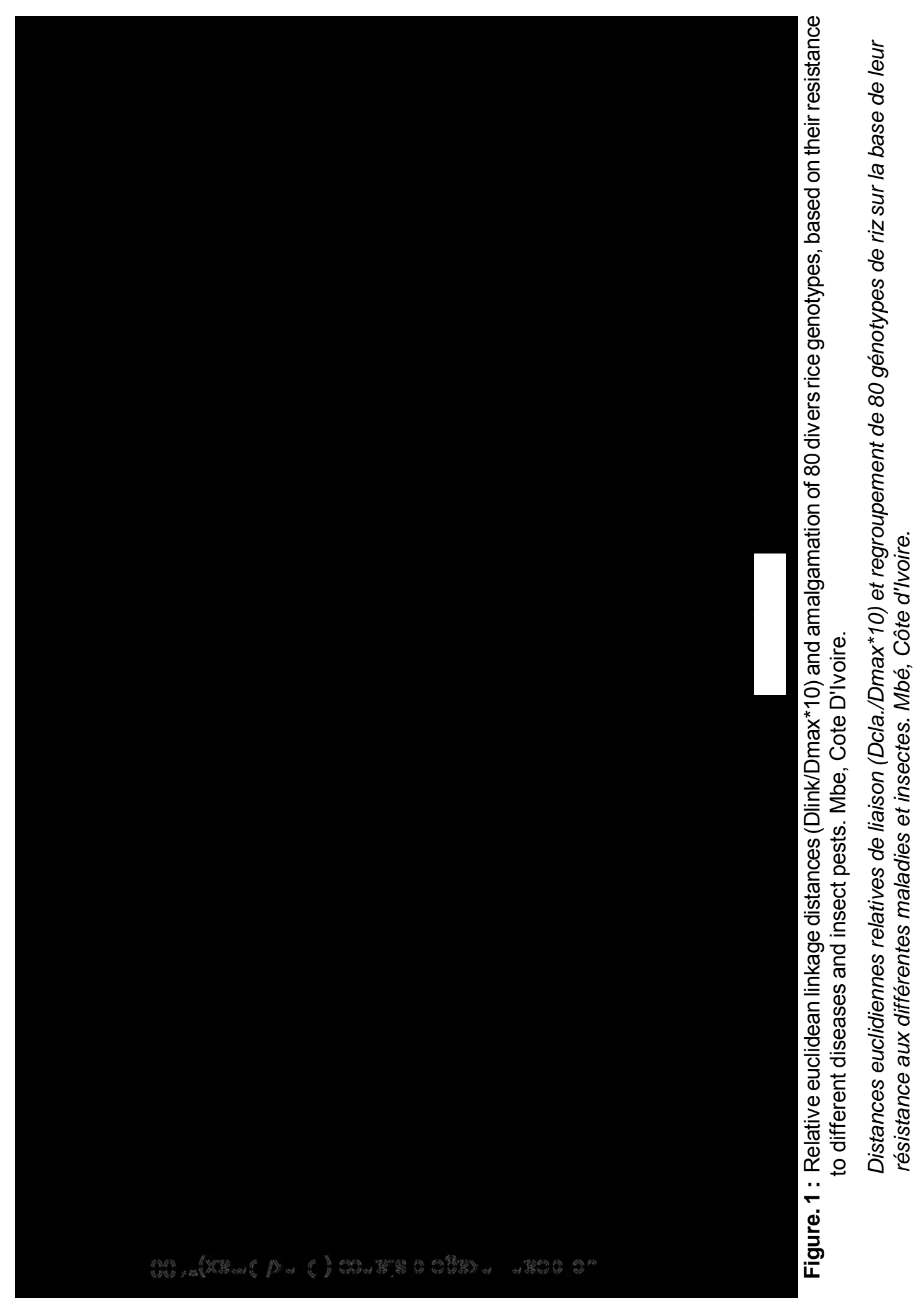




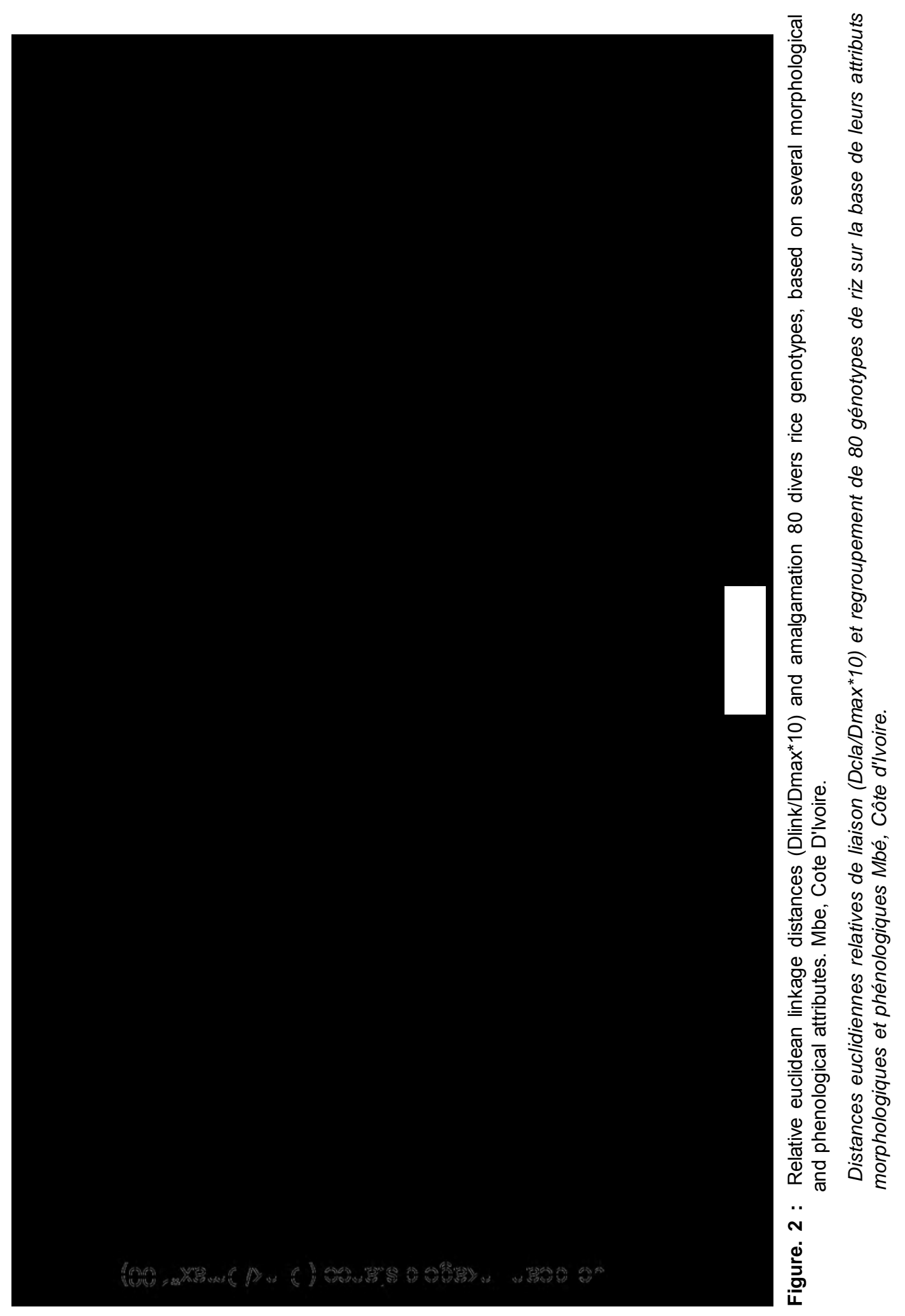




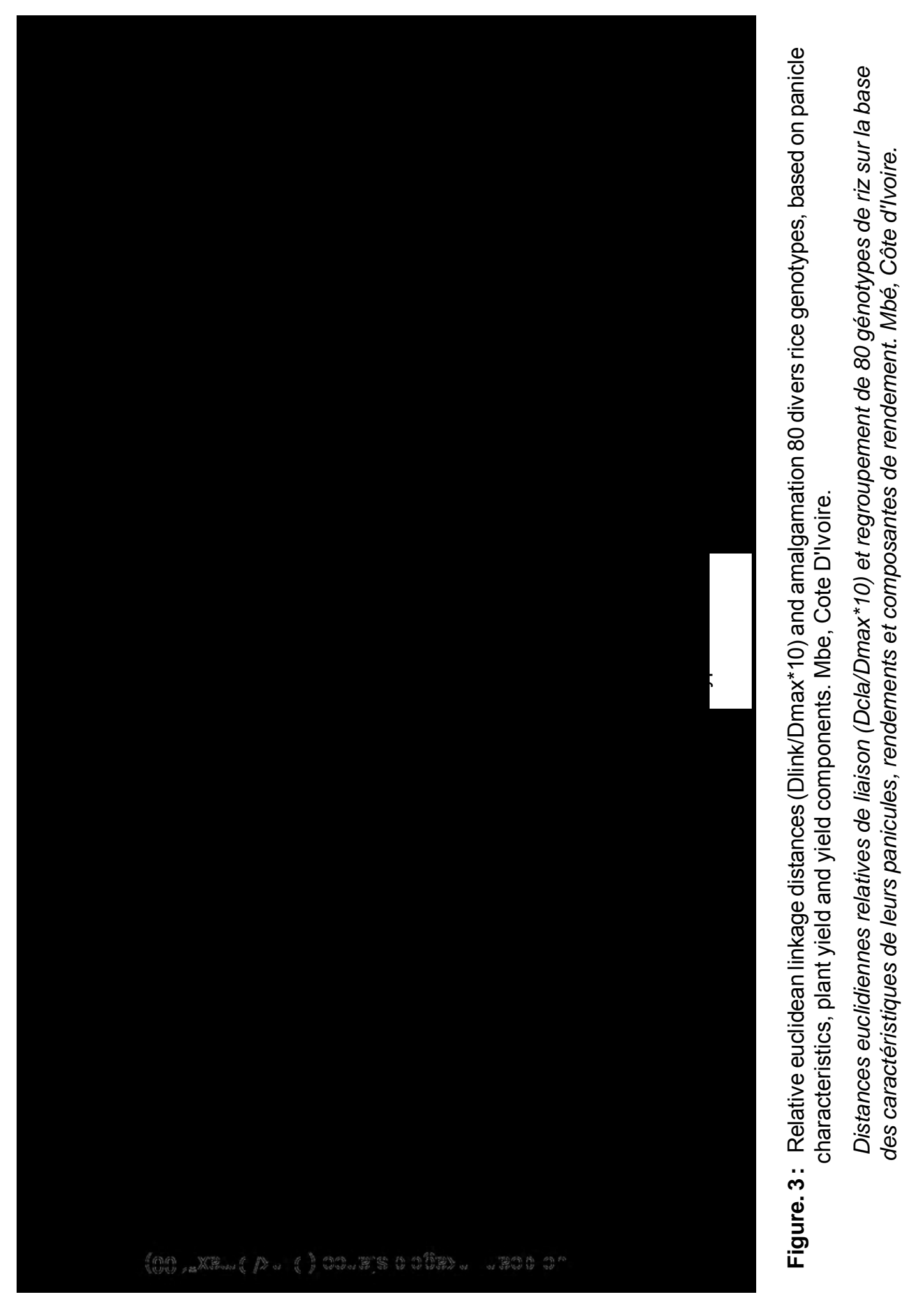




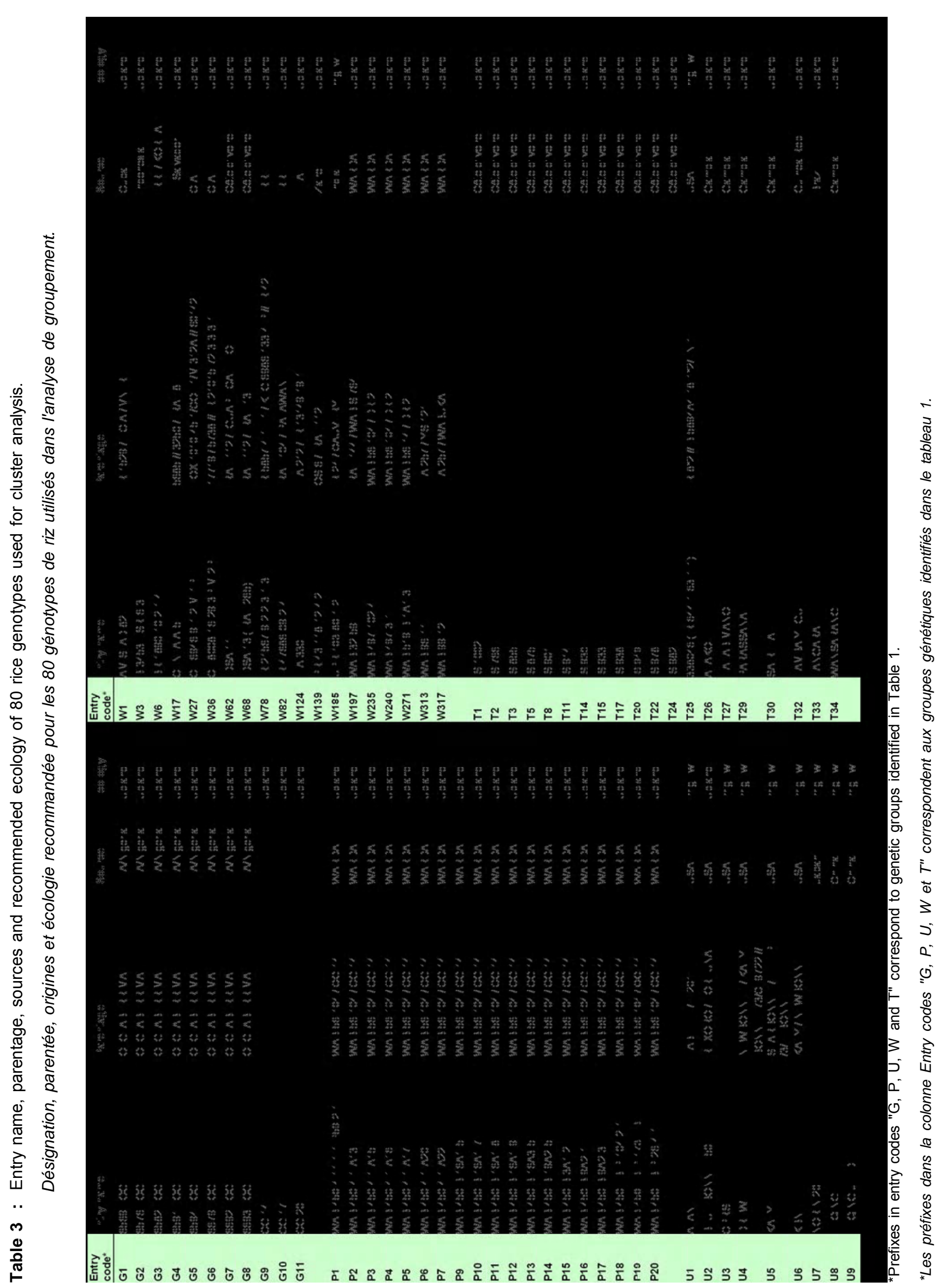


of germplasm to screen for specific objectives. The challenge therefore is to ensure that the 'fewer' number of germplasm to be dispatched are diverse enough for the specific breeding objective. K-mean clustering is a useful toll in this regard.

Five clusters created from the K-mean clustering procedure and members of each group distributed following their on disease reaction are presented in table 4 . Figure 4 shows the reaction of each group to diseases. Glaberrimas are concentrated in clusters 1 and 2, whereas improved sativas are nearly spread uniformly across the clusters. Most interspecific progenies (12 out of 29) belong to cluster 2 (table 4).

All the clusters except cluster 4 showed tolerance to leaf blast. Members of cluster 4 are mainly traditional sativas (6 out of 12), and three progenies (table 4 ). Cluster 5 is susceptible to gall midge, brown spot and stem borer attacks. Members of the group are distributed between the improved sativas (6 out of 9), 2 interspecific progenies and one USA variety.

K-means clustering based on morphophysiological properties (table 5 and figure 5) show a neater classification than the one based on diseases reaction. This is perhaps because the traits measured were quantitative and not "subjective» scorings used for diseases and pests. Traditional sativas are clumped in cluster 5 (13 out of 20 entries), whereas 6 out of the 9 USA varieties are in cluster 1 , along with improved sativas (9 entries) and interspecific progenies ( 6 entries). The glaberrimas are concentrated in cluster 2 (8 out of 11 entries). The morphological characteristics of the 5 clusters (cluster means values) are presented in figure 5 .

Seedling vigor did not vary much. Cluster means were between 1.5 and 2.5 (not shown on graphs due to scaling). SLA was the lowest in cluster 1 , while cluster 5 is characterized by mean time to flowering in 100 days. Plants reaching mean height of $100-110 \mathrm{~cm}$ were seen in cluster 2 (mainly glaberrimas) and cluster 5 (mainly traditional sativas). The best and the worst tillering ability were found respectively among genotypes in cluster 2 (mean tiller /plant $=7$ ) and cluster 5 (mean tiller / plant $=5$ ).

In cluster 1 we have entries of which the mean leaf blast scores are $<1$. Cluster 3 did not show any symptom of leaf blast. Members of cluster 4 rated susceptible (mean score of 4 ) to leaf blast. Six out of the 10 members of this group are improved sativas, the other others being 2 interspecific progenies and 2 USA materials. Clusters 2, 3 and 5 are susceptible to all diseases, whereas Cluster 4, consisting mainly of interspecific progenies ( 11 out of 25 entries) is characterized by high disease resistance (disease scores < 2.0).

Reclassification based on morphological traits and members of each cluster are shown in table 5. Figure 5 shows the characteristics of the clusters amalgated by morphophysiological attributes. Cluster 1 , where most of the traditional sativas are grouped (17 out of 29 members), most glaberrima (7 out of 11 glaberrima located here) and 4 interspecific progenies are characterized by the tallest heights (mean $105 \mathrm{~cm}$ ), longer days to flower (90 days) and high SLA (52 $\mathrm{m}^{2}$ leaf /g leaf). This cluster had also the best seedling vigor compared to other clusters. Cluster 5, comprising mainly of progenies ( 3 out of 5 members) showed high SLA also (figure 5). Cluster 2, is characterized by a high tillering rate. This is not surprising because this group is predominantly composed of improved sativas (11 out of 16 members) and 2 glaberrimas.

When classified on panicle and yield attributes, genetic groups are clearly different (Table 6). Nine glaberrimas, as well as 7 improved sativas and 7 interspecific progenies were found to be similar with respect to yield and panicle characteristics. This cluster had high mean plant yield, moderate spikelet number, and moderately low secondary branching. Cluster 1 and 2 where other improved sativas, and interspecific progenies are mainly located are characterized by high spikelet number (means = 100 to 150 per panicle), high secondary branching (mean 27 to 33) (figure 6). Analysis showed that cluster 5 , with seven members is composed principally of traditional sativas (6 out of 7 members) and one improved sativa W124 (ITA330). This cluster was found to have the lowest primary and secondary branching, the lowest panicle length, the lowest spikelet number, harvest index and plant yield. 


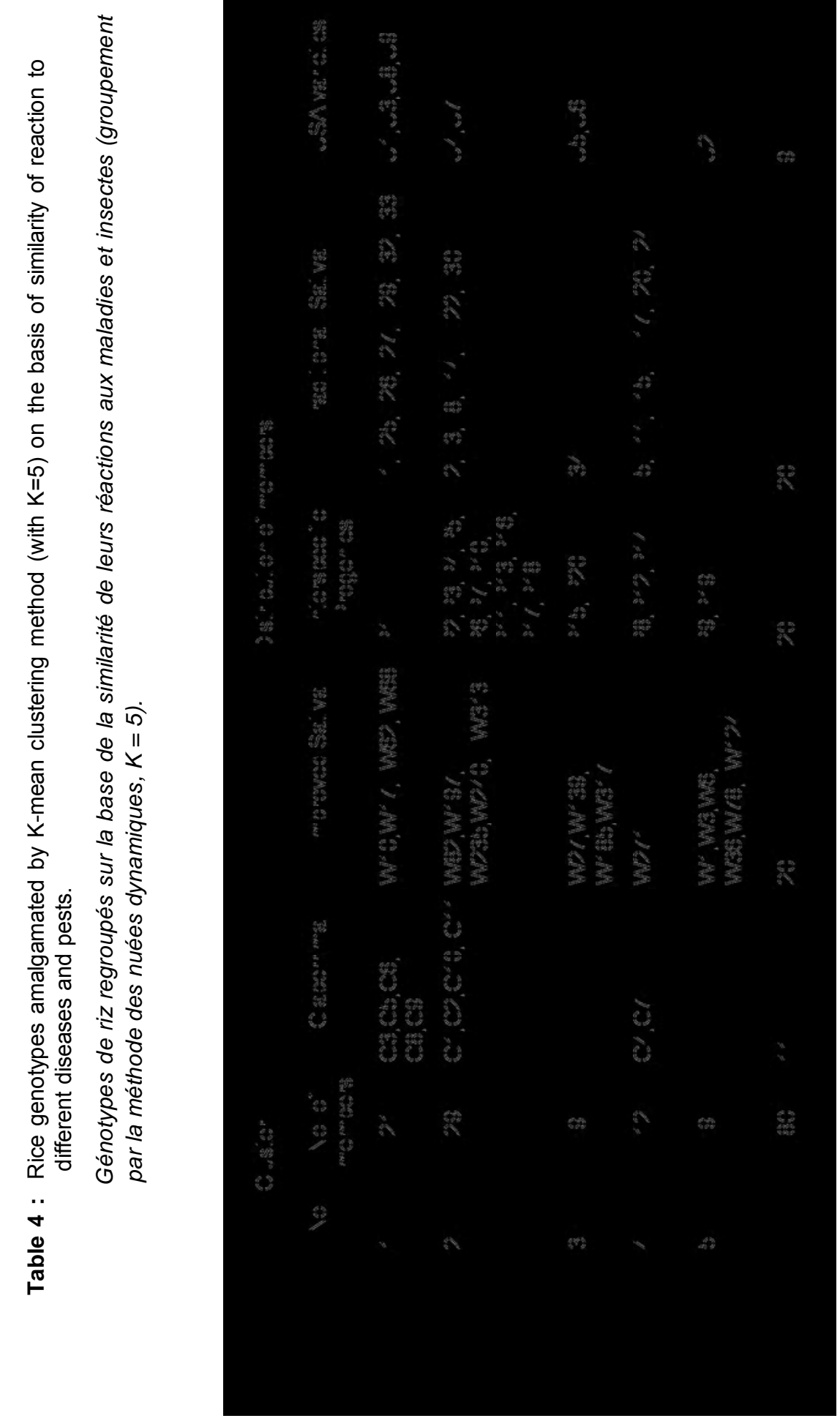




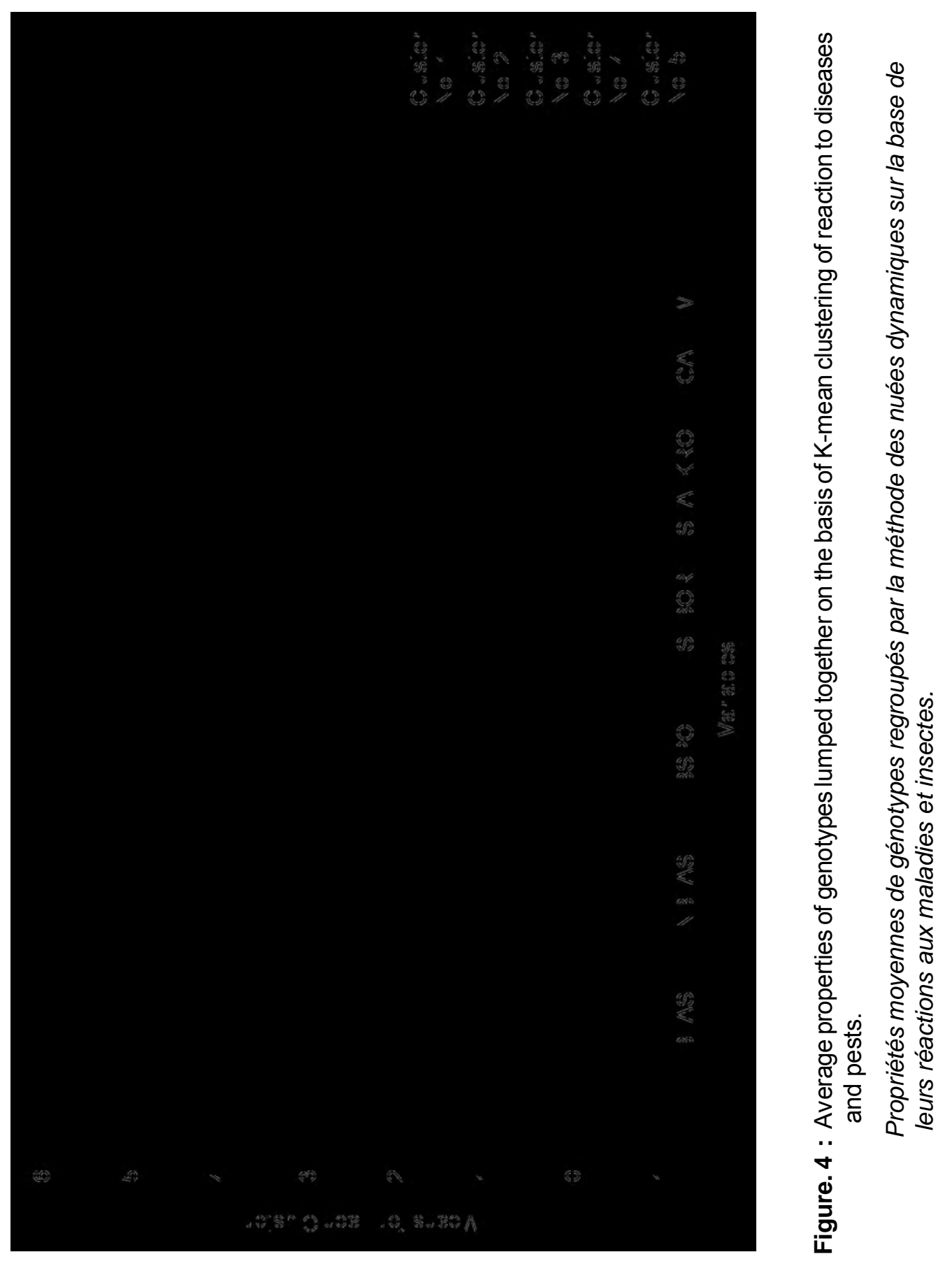




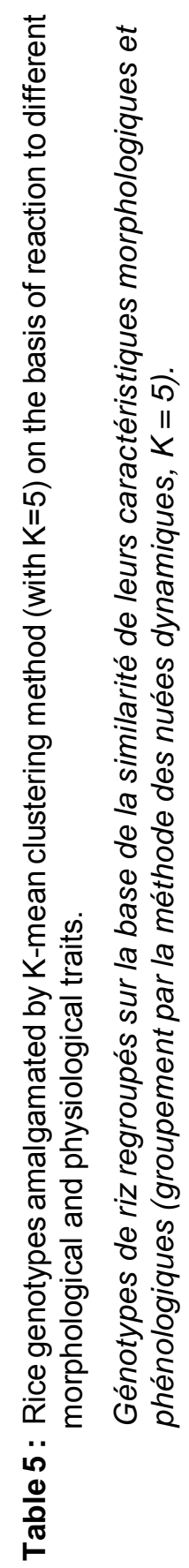




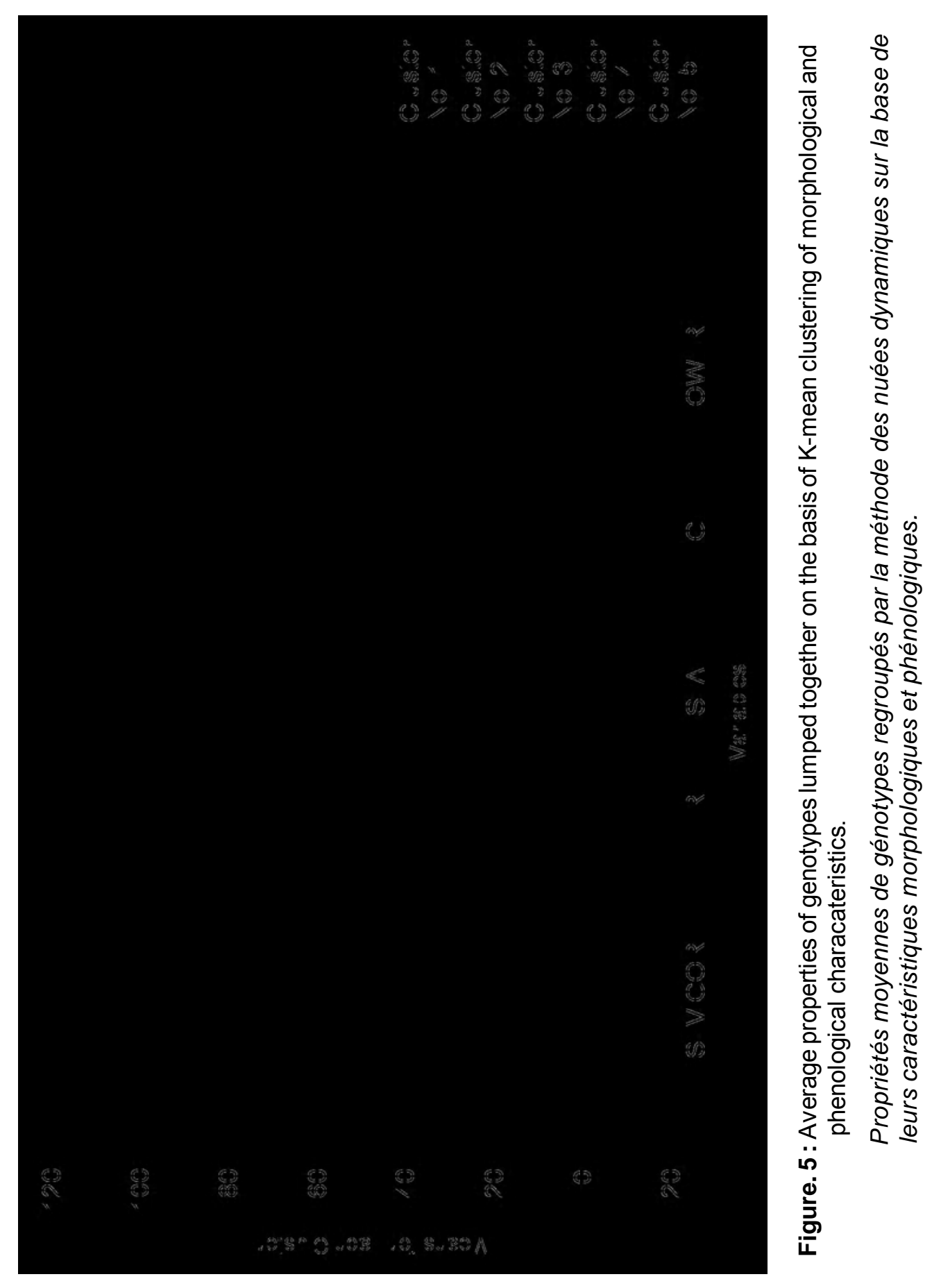



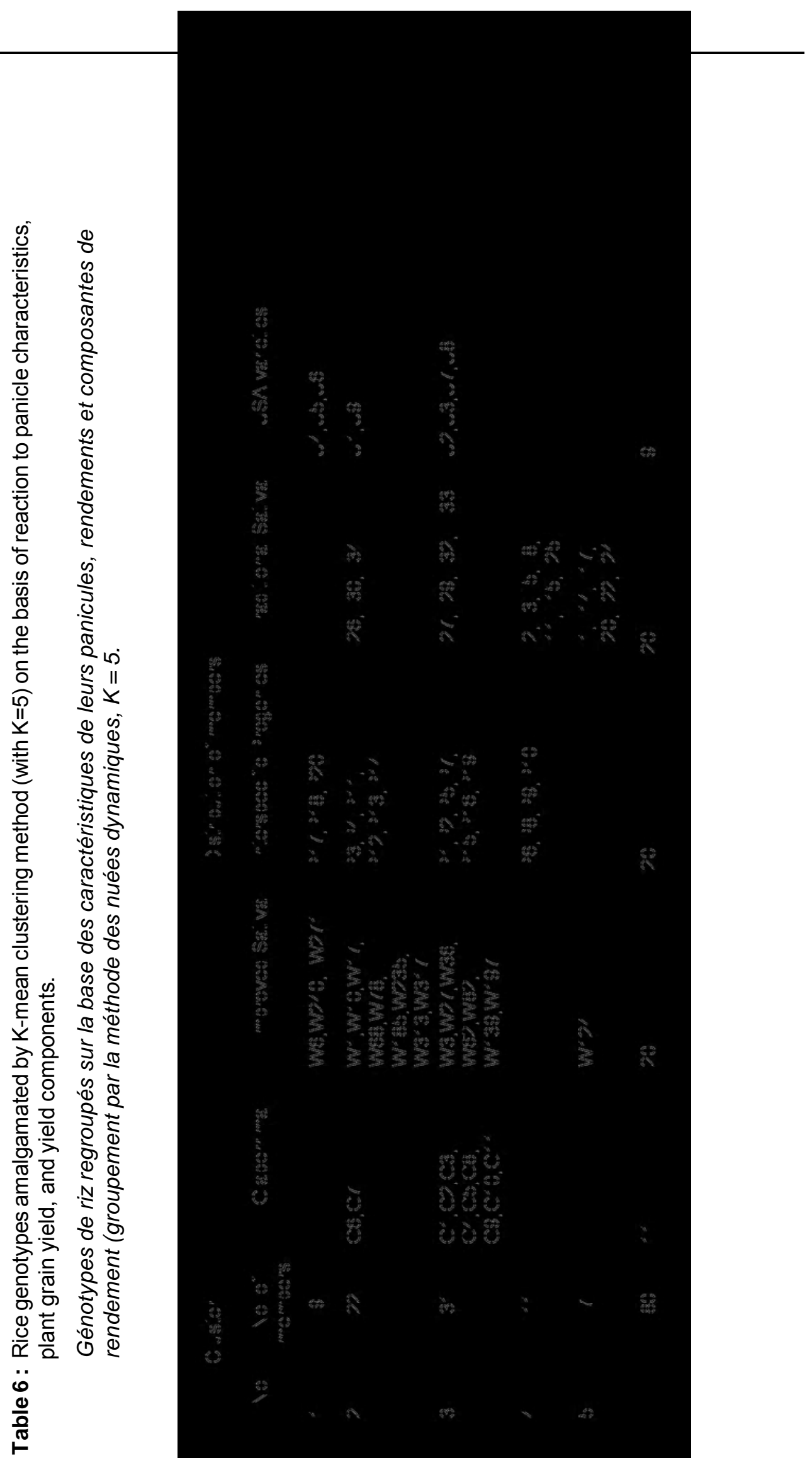


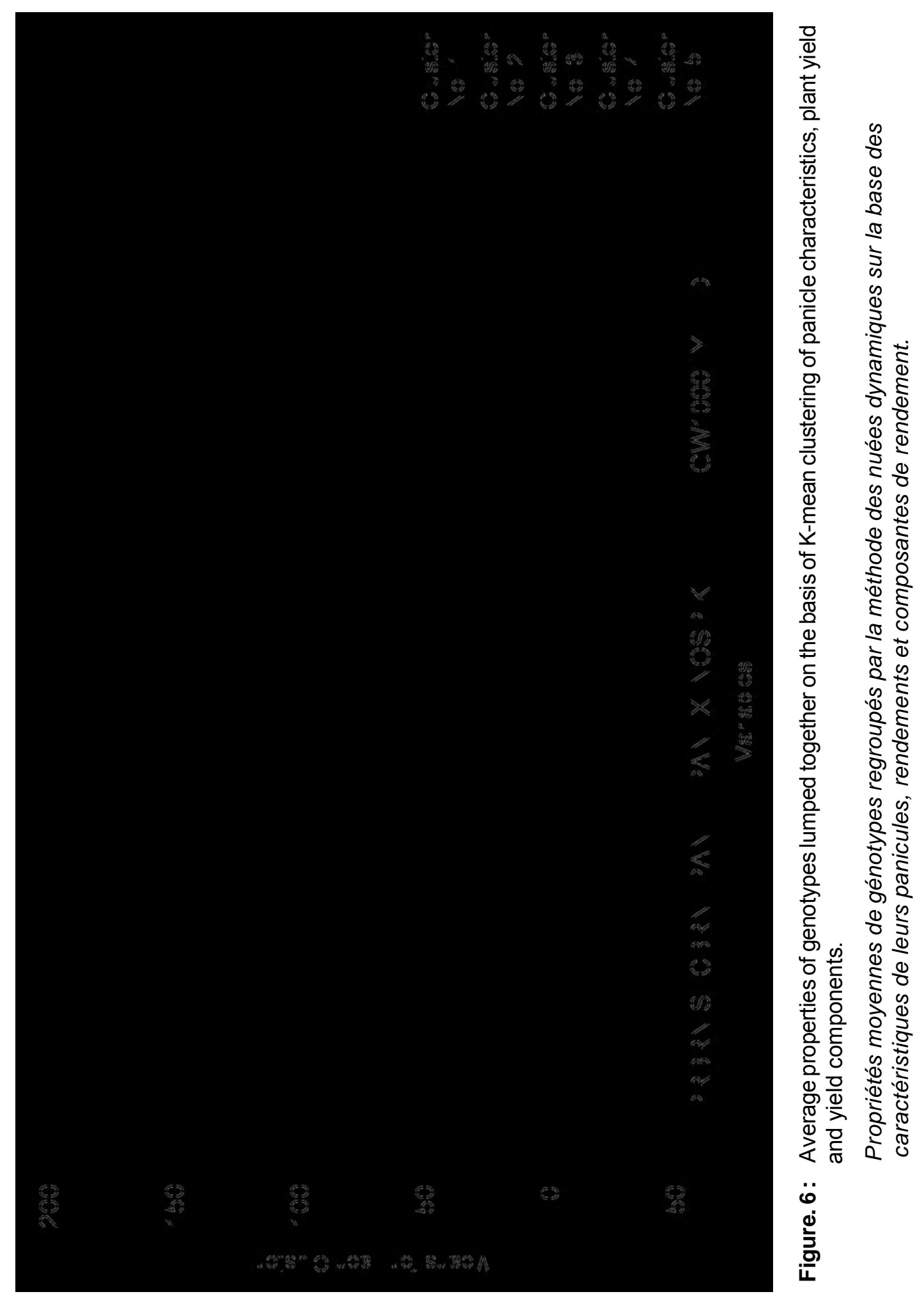




\section{CONCLUSION}

Regional and national programs involved in improving rice yields in less favorable rice environments in West Africa, require access to wide range of germplasm for screening, selection and use in their breeding objectives. The germplasm characterization studies reported here clearly showed that a high suitability of a particular genetic group resistant to diseases, morphological type or yield attribute does not equate to wide genetic variability within that group. The studies also showed that the magnitude of variability was not the same for all traits. Some traits are more diverse than others, indicating that breeding programs have different chances of rapidly achieving success with these traits.

Comparison within and between five rice germplasms obtained from tropical and temperate regions revealed an overlap with respect to the traits characterized. Cluster analysis showed for example, that most glaberrimas and interspecific progenies possess tolerance or resistance to leaf blast, stem-borer and gall midge attacks. Interspecific progenies and improved sativas are diverse with respect to panicle and yield attributes.

The study revealed that interspecific progenies were classified between their two parental groups (the glaberrimas and the improved sativas), (Jones et al., 1997). Cluster analysis showed progenies spreading between the extremes where both parents occurred. Earlier, Jones et al. (1997) reported that progenies inherited from glaberrima parents the characters of vigor, high tillering, early growth duration and high SLA. From the sativa parents they took characters controlling yield and panicle attributes.

\section{REFERENCES}

ABAMU (F.J.), (K.) ALLURI and (D.V.) SESHU. 1992. Reaction of rice genotypes of different origins and genealogy to blast $(\mathrm{BI})$ disease in Nigeria. International Rice Research Newsletter (IRRN) $17:$ 10-11.

JOHNSON (D. E), (M.P.) JONES, (M.) DINGKUHN and (M.C.) MAHAMANE. 1996. The effect of weed competition on cultivars of Oryza glaberrima, O. Sativa and an Interspecific hybrid Rice. Interspecific Hybridization: Progress and Prospects, WARDA/ADRAO

JOHNSON, (D.E.), (M.P.) JONES, (M.) DINGKUHN and (M.C.) MAHAMANE. 1997. The response of O.glaberrima, O. Sativa and an interspecific hybrid rice cultivar to weed competition. The 1997 Brighton crop protection conference. Weeds $1: 197-201$.

JONES (M.P.), (M.) DINGKUHN, (G.K.) ALUKO and (M.) SEMON. 1996. Using backcrossing and doubled Haploid Breeding to generate Weed competitive Rices from $O$. sativa $\mathrm{L}$. X O. Glaberrima Steud. Genepools, Interspecific hybridization: Progress and Prospects, WARDA/ADRAO.

JONES (M.P.), (M.) SEMON and (G.K.) ALUKO. 1997. Diversity and Potential of Oryza glaberrima Steud in Upland Rice Breeding. Breeding Science $47: 395-398$.

OOKAWA (T.) and (K.) ISHIHARA. 1993. Varietal differences in physical characteristics of culm related to lodging resistance in paddy rice. Crop Production Technology in Asia. $1993: 133-141$.

SINGH (B.N.), (A.T.) MAJI, (N.Q.) NG, (C.) PAUL, (C.) WILLIAMS and (M.N.) UKWUNGWU.1996. Utilization of Oryza glaberrima Genetic Resources for Lowland rice Improvement. Interspecific Hybridization: Progress and Prospects, WARDA/ADRAO. 